\title{
199. Chemoreception of the Lateral-line Organ of Xenopus laevis
}

\author{
By Norihiko ONodA,**) Toru Hashimoto,*) \\ and Yasuji KATSUKI**)
}

(Comm. by Koiti МотокAWA, M. J. A., Oct. 12, 1970)

The lateral-line organ of aquatic vertebrates has been known to be a mechanoreceptor. In 1969 Katsuki et al.,7),8) however, reported that the pit organ (a free neuromast) of the shark has dual functions, the mechanoreception and the chemoreception. On the other hand the ordinary canal organ is highly mechano-sensitive, but not responsive to any chemical stimuli.

In the present article, we will report that the lateral-line organ of the South African clawed toad, Xenopus laevis, has also dual functions, as observed in fish. This organ is provided with the cupula, a well-defined accessory membraneous structure of the lateral-line receptor. Therefore it was believed to be a mechanoreceptor. ${ }^{3)-6)}$

Material and methods. The material used was 10 clawed toads of $5-7 \mathrm{~cm}$ in the body length, which were supplied through the courtesy of Institute of Endocrinology, Gunma University. The animal was decerebrated at the cervical level and fixed on a board in the prone position. When the dorsal skin of the animal was cut by $5-10 \mathrm{~mm}$ along the lateral-line near the forelimb, nerve trunks were seen innervating the upper and middle row of the lateral-line organ. After one of the nerve trunks was exposed, the distal cut end was separated into many thin bundles with a pair of sharpened tweezers under a binocular microscope.

The methods for recording neural responses and stimulating the end organ were the same as described in the previous papers. ${ }^{7)-9}$ ) The temporal pattern of the response was measured and recorded on a strip chart by the use of the electronic rate meter. ${ }^{9)}$

Results. Spontaneous discharges of the lateral-line nerve fiber had a steady rate for a considerable time. We could know the location of the receptor rather easily, because a gentle touch on the skin caused a typical burst-like discharge. When an ionic solution was applied to a confined receptive field, the discharge of the nerve fiber

*) Institute for Medical and Dental Engineering, Tokyo Medical and Dental University, 2-3-10 Surugadai, Kanda, Chiyoda-ku, Tokyo.

**) Department of Physiology, Tokyo Medical and Dental University, Tokyo. 
innervating the receptor increased very rapidly. When the end organ was washed with distilled water, the increased rate of discharge returned quickly to the level of the spontaneous discharge rate. These processes were reversible. In Fig. 1 is shown the discharge pattern of a single lateral-line nerve fiber recorded by a chart recorder through an electronic rate meter, where $\mathrm{KCl}$ solutions of various molar concentrations were applied to the receptive field of

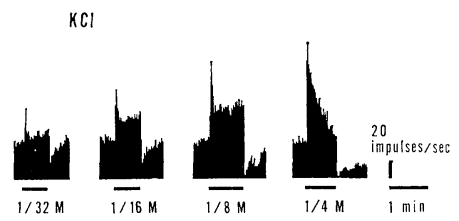

Fig. 1. Single fiber response of the lateral-line nerve of Xenopus, measured by a rate meter, to application of $\mathrm{KCl}$ solutions. Abscissa gives time; a horizontal bar shows the period of application of $\mathrm{KCl}$ solution. Ordinate gives the number of impulses per second; a perpendicular bar shows 20 impulses per second.

the lateral-line organ on the skin surface. This receptor was weakly stimulated by a $1 / 32 \mathrm{M} \mathrm{KCl}$ solution. An initial phasic increase, which might be partly due to the mechano-stimulation brought about by the application of the salt solution, appeared in a few seconds and soon the discharge rate fell gradually to a level of the continuous steady state. A $1 / 32 \mathrm{M} \mathrm{KCl}$ solution was the threshold stimulus of this receptor. With application of a $1 / 8 \mathrm{M} \mathrm{KCl}$ solution the discharge rate increased twice as much, compared with the spontaneous level. When a $1 / 4 \mathrm{M} \mathrm{KCl}$ solution was applied, the nerve response did not show a steady rate and the discharge rate tended to drop gradually. With rinsing by distilled water, the discharge rate decreased down to zero quickly and returned up to the spontaneous level after a while. The higher the concentration of the applied $\mathrm{KCl}$ solution was, the slower the gradual recovery to the spontaneous level became. With application of a $1 / 4 \mathrm{M} \mathrm{KCl}$ solution it took about 2 minutes to recover up to the spontaneous level again.

The magnitude of responses of Fig. 1 is plotted in Fig. 2 (crosses). The discharge rate increases in a linear function of the molar concentration of the applied. $\mathrm{KCl}$ solution in a logarithmic scale. Many unitary responses, however, showed the linear relation only in the lower concentration of the applied solution.

In the present experiment other ionic solutions of various kinds were used; $\mathrm{NH}_{4} \mathrm{Cl}, \mathrm{NaCl}, \mathrm{NaNO}_{3}, \mathrm{NaCH}_{3} \mathrm{SO}_{4}, \mathrm{Na}$-glutamate, $\mathrm{CaCl}_{2}$, $\mathrm{MgCl}_{2}$. Effects of $\mathrm{NH}_{4} \mathrm{Cl}$ solutions were almost similar to that of 


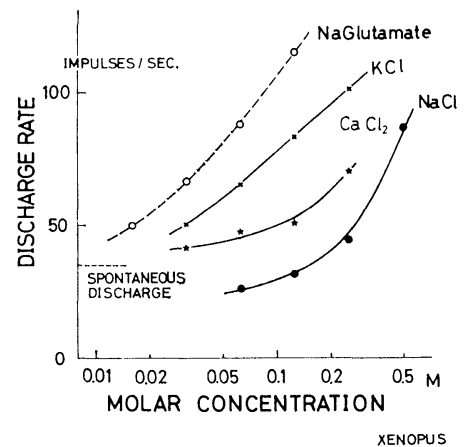

Fig. 2. Effects of various salt solutions on the lateralline organ of Xenopus. All responses were obtained from the same receptor. Ordinate gives the molar concentration and abscissa the number of impulses per second. The dotted line near the vertical axis shows the spontaneous discharge rate. Responses to $\mathrm{KCl}, \mathrm{NaCl}, \mathrm{Na}-$ glutamate, and $\mathrm{CaCl}_{2}$ solutions are shown by crosses, filled circles, open circles, and stars, respectively.

$\mathrm{KCl}$ solutions. Effects of $\mathrm{NaCl}$ solution are shown in Fig. 2 (filled circles). There were the following large differences between the response of $\mathrm{KCl}$ and that of $\mathrm{NaCl}$ solution.

1) Contrary to the increase of discharge by $\mathrm{KCl}$ application, a decrease of the discharge rate was noticed, when $1 / 16 \mathrm{M}$ or $1 / 8 \mathrm{M}$ $\mathrm{NaCl}$ solution was applied to the same receptor. The firing rate was lower than the spontaneous discharges.

2) The distilled water effect (DWE) reported by Konishi et al. ${ }^{11)}$ was observed after $\mathrm{NaCl}$ application when the receptive field was rinsed with distilled water.

3) The discharge rate became slightly higher than the spontaneous one, when a concentrated $\mathrm{NaCl}$ solution, such as $1 / 4 \mathrm{M}$ was applied to the receptive field.

The effects of $\mathrm{NaNO}_{3}$ and $\mathrm{NaCH}_{3} \mathrm{SO}_{4}$ to the same receptor were also examined. The results were similar to $\mathrm{NaCl}$. Responses to Na-glutamate are shown in Fig. 2 (open circles). It was the most effective among salts applied and its effect bore resemblance to those of $\mathrm{KCl}$ and $\mathrm{NH}_{4} \mathrm{Cl}$. As reported already ${ }^{7)-9)}$ responses of the pit organ of the shark or some other teleosts to monovalent cations were suppressed by divalent cations and tetrodotoxin. However, in Xenopus the suppressive effect could not be found and moreover divalent cations themselves stimulated the receptors. Responses to $\mathrm{CaCl}_{2}$ are also shown in Fig. 2 (stars). $\mathrm{MgCl}_{2}$ (not shown) was also effective, but weaker than $\mathrm{CaCl}_{2}$.

The interesting effect was that the liver extract was able to 
stimulate the same receptor as ionic solutions did. For 1 minute after application, there was a slow rise of the discharge rate and it was saturated with only double rate relative to the spontaneous level. The discharge rate quickly returned to the spontaneous level, when the receptive field was washed with distilled water. Whenever liver slices were given as baits into a water tank, all animals there were excited, swam about in the tank and finally located the liver pieces. Our results may explain without discrepancy their feeding behavior.

An application of the tetrodotoxin solution on the receptive field caused no remarkable effect on the responses of ionic solutions, even when the same solution was enough concentrated to block the nerve conduction. Dihydrostreptomycin sulfate was tested on the same end organs, but nothing happened on the responses of ionic solutions.

Effects of glucose, sucrose and quinine hydrochloride as gustatory substances were also studied, but they could not stimulate this lateral-line organ.

Discussion. Studies on the detailed structure of the free standing lateral-line organ of Xenopus have already been performed by several electronmicroscopists. ${ }^{3-6)}$ It has been known that the lateralline organ of Xenopus is not completely the same as either the free or the canal neuromast of fish. However, that of Xenopus has a cupula and each sensory cell is provided with a kinocilium and many stereocilia like that of fish. Nobody has observed the taste bud-like structure in the lateral-line organ of Xenopus. From the morphological point of view, this free standing organ is nothing but a mechanoreceptor. But as described above, this organ more or less responded to chemical stimulation. We would like to emphasize again that such responses to chemicals were not artifacts, because the concentrated tetrodotoxin that was able to block the nerve conduction did not suppress the chemical responses at all and $\mathrm{Ca}^{++}$and $\mathrm{Mg}^{++}$, that do not stimulate the nerve fiber so sensitively in natural situation, stimulated the end organ.

The animal lives always in water for his whole life, but breathes air through the lung, while his tongue stays undeveloped. Therefore the lateral-line organ of this animal is supposed to be a detector of the small change of ionic concentrations in the environmental water surrounding himself. The threshold concentration of the $\mathrm{NaCl}$ solution for the gustatory receptor in the palatal organ of the carp ${ }^{10)}$ was not so different from the sensitivity of the tongue of the ordinary frog. ${ }^{12)}$ The threshold for $\mathrm{K}^{+}$effect was much lower than that for $\mathrm{Na}^{+}$. The response to the chemicals of the fish lateral-line organ was also similar to the gustatory response of the frog tongue. ${ }^{12)}$ Our 
result obtained from the lateral-line organ of Xenopus looks similar, intrinsically the same as the gustatory sensation, so that the end organ of Xenopus may be considered to be an excellent detector of the salt concentration in the watery environment.

Although further studies are needed, the authors are of opinion that the lateral-line organ of Xenopus may be one of the main receptors for the common chemical sense ${ }^{1)}$ or the external taste sense. $^{2)}$

Acknowledgement. This research was supported in part by a Grant from the Ministry of Education. We express thanks to Professor K. Hanaoka, Institute of Endocrinology, Gunma University and to Dr. K. Ishii, Department of Physiology, Fukushima Medical College, for supplying the experimental animals.

\section{References}

1) Bardach, J. E. (1967): The chemical senses and food intake in the lower vertebrate. The Chemical Senses and Nutrition (ed. by M. R. Kare and O. Maller, Johns Hopkins Press), 19-43.

2) Bardach, J. E., Fujiya, M., and Holl, A. (1967): Investigation of external chemoreceptors of fishes. Olfaction and Taste II (ed. by T. Hayashi, Pergamon Press), 647-666.

3) Dijkgraaf, S. (1963): The functioning and significance of the lateral-line organs. Biol. Rev., 38, 51-105.

4) Flock, A. (1966): Ultrastructure and function in the lateral line organs (ed. by P. H. Cahn, Indiana University Press), 163-197.

5) Görner, P. (1961): Beitrag zum Bau und zur Arbeitsweise des Seitenorgans von Xenopus laevis. Verhandl. Deut. Zool. Ges. Saarbrücken, 193-198.

6) Harris, G. G., and Milne, D. C. (1966): Input-output characteristics of the lateral-line sense organs of Xenopus laevis. J. Acoust. Soc. Am., 40 $32-42$.

7) Katsuki, Y., Yanagisawa, T., Tester, A. L., and Kendall, J. I. (1969) : Shark pit organs: Response to chemicals. Science, 163, 405-407.

8) Katsuki, Y., and Hashimoto, T. (1969): Chemoreception in the lateral-line system of the bony fish. Proc. Japan Acad., 45, 209-214.

9) Katsuki, Y., Hashimoto, T., and Yanagisawa, K. (1970): The lateral line organ of shark as a chemoreceptor. Advances in Biophysics (ed. by $M$. Kotani, University of Tokyo Press), 1, 1-51.

10) Konishi, J., and Zotterman, Y. (1961): Taste functions in the carp, an electrophysiological study on gustatory fibers. Acta Physiol. Scand., 52, $150-161$.

11) Konishi, J. (1966): Fresh water fish chemoreceptors responsive to dilute solutions of electrolytes. J. Gen. Physiol., 49, 1241-1264.

12) Kusano, K. (1960): Analysis of the single unit activity of gustatory receptors in the frog tongue. Jap. J. Physiol., 10, 620-633. 